\title{
MYRICETIN NANO-PHYTOSOMES PEEL-OFF GEL MASK FORMULATION AS ANTIOXIDANT
}

\author{
NUR AINI DEWI PURNAMASARI ${ }^{*}$, MUHAMMAD DZAKWAN , GANET EKO PRAMUKANTORO², RACHMAT \\ MAULUDIN $^{3}$, ELFAHMI $^{4}$
}

\begin{abstract}
${ }^{1}$ Departement of Pharmaceutics and Pharmaceutical Technology, Faculty of Pharmacy, Setia Budi University, Surakarta, Indonesia, ${ }^{2}$ Departement of Clinical Pharmacy, Faculty of Pharmacy, Setia Budi University, Surakarta, Indonesia, 3Departement of Pharmaceutic, School of Pharmacy, Bandung Institute of Technology, Bandung, Indonesia, ${ }^{4}$ Departement of Pharmaceutical Biology, School of Pharmacy, Bandung Institute of Technology, Bandung, Indonesia "Email: aini_farmasi2008@yahoo.com
\end{abstract}

Received: 26 Nov 2020, Revised and Accepted: 09 Jun 2021

\begin{abstract}
Objective: Peel-off gel mask is an alternative preparation which can increase the convenience of use and is expected to increase the antioxidant activity of myricetin nano-phytosomes. Myricetin has various activities, namely as a natural antioxidant, anti-inflammatory, allergy, and anti-cancer. This study aims to determine the nano-phytosome myricetin can be formulated into a gel peel-off mask, determine the concentration of PVA which has the best physical properties of the gel peel-off mask, and determine the antioxidant activity.
\end{abstract}

Methods: The thin layer hydration method was used to manufacture Myricetin nano-phytosomes, then dried using the freeze-drying method. The resulting nano-phytosome characterization included particle size, polydispersion index, zeta potential and absorption efficiency. Peel-off gel mask were made with variations in the concentration of the PVA gelling agent, namely F1 3.5\%, F2 7\%, F3 14\%. The resulting peel-off gel mask was tested for physical quality including organoleptic test, homogeneity, $\mathrm{pH}$, viscosity, adhesion, drying time and testing for antioxidant activity.

Results: The resulting peel-off gel mask has the good physical quality and met the existing requirements, where the different PVA concentrations resulted in different physical qualities, the higher the PVA, the faster the dry time. All three formulas exhibited very strong antioxidant activity based on DPPH assay with IC 50 value of 14.8 ppm (F1), 15.37 ppm (F2), and 15.87 ppm (F3).

Conclusion: Myricetin nano-phytosomes can be formulated into a gel peel-off mask, Formula 2 with a 7\% concentration of PVA produces the best physical quality of the peel-off gel mask, the three gel peel-off mask formulas have excellent antioxidant activity.

Keyword: Peel-off gel mask, Myricetin nano-phytosomes, PVA, Antioxidant

(c) 2021 The Authors. Published by Innovare Academic Sciences Pvt Ltd. This is an open access article under the CC BY license (https://creativecommons.org/licenses/by/4.0/) DOI: https://dx.doi.org/10.22159/ijap.2021v13i4.40376. Journal homepage: https://innovareacademics.in/journals/index.php/ijap

\section{INTRODUCTION}

Cosmetics are a necessity to look attractive, healthy and fit. Formulations from natural ingredients in the form of cosmetic dosages can increase the convenience of use and acceptance in society [1]. Facial cosmetics are available in various dosage forms, one of which is the peel-off mask [2]. The peel-off gel mask is a preparation that is easy to apply because it is in the form of a gel, and in a certain time it will dry out immediately and can be easily removed or removed like an elastic membrane [3]. Gel preparations were chosen because they do not contain oil but have a high enough water content so that they can hydrate the stratum corneum [4]. The base for the peel-off gel mask used is polyvinyl alcohol (PVA). PVA is the basic ingredient for a peel-off gel mask which has the advantage of being able to produce a homogeneous gel with its active ingredients and can be used as a cosmetic preparation. PVA can also moisturize the skin, remove dead skin cells, and clean the skin [5]. The concentration of PVA used as a gelling agent was 2.5\%-17.5\% [6].

The development of medicinal preparations technology derived from natural ingredients is growing rapidly. Often with advances in science and technology, scientists have researched compounds that are useful as antioxidants. Antioxidants are compounds that can inhibit oxidation reactions by binding to free radicals and highly reactive molecules, so that inhibit cell damage. Antioxidants are also used to prevent premature aging [7]. One of the compounds that have antioxidant activity is myricetin.

Myricetin is a natural flavonoid with hydroxyl groups at positions 3, 5, 7, 3 ', 4' and 5'. Myricetin is widely contained in vegetables, tea, fruits and medicinal plants. Flavonols are flavonoid class compounds that have potential as antioxidants and have bioactivity as drugs. Myricetin has various activities, namely as a natural antioxidant, antiinflammatory, allergy, and anti-cancer [8]. However, myricetin has a very low systemic bioavailability of $10-44 \%$ due to its low water solubility $(0.002 \mathrm{mg} / \mathrm{ml})$ [9]. The latest development of the Drug Delivery System has the advantage of enhancing the penetration properties of the skin. One of the developments in the Drug Delivery System in transdermal delivery is the vesicular system, such as liposomes, niosomes, ethosomes, transfersom and phytosomes [10].

The phytosomes are an integral part of the membrane, where molecules are anchored through chemical bonds to the head of phospholipids [11]. The composition of phytosomes is safe its components are accepted for use in the pharmaceutical field, and the absorption and bioavailability of water-soluble natural materials are increasing. This results in a better therapeutic effect [12]. Nanoparticles are particles of colloidal size with diameters ranging from 1-1000 nm and may contain, absorb or disperse drugs [13]. To increase the solubility of myricetin, it is made in a nano form, namely nano-phytosome myricetin. Nano-phytosomes are one of the latest lipid-based nano-carriers [14].

This study aims to determine that myricetin nano-phytosome can be formulated into a gel peel-off mask, determine the concentration of PVA which has the best physical properties of the myricetin nanophytosome peel-off gel mask, and determine its antioxidant activity. The novelty of the research is the gel peel-off mask formulated with a variety of PVA derived from natural ingredients myricetin which has been made with a nano-phytosome drug carrier system.

\section{MATERIALS AND METHODS}

\section{Materials}

The sample materials used in this study were myricetin (Tocris, China), Phospholipon 90 G (Lipoid, Germany), cholesterol (Brand), ethanol (Brand), chloroform (Brand), aquadest pro injection (PT. Ikapharmindo Putramas), PVA (Brataco, Indonesia), Carbopol, TEA, Opthipen and Propylenglikol. The tools used in this study were the UV-Vis Spectrophotometer (Genesys 10s, Thermo scientific), rotary evaporator 
(Heidolph), sonicator probe (QSonica, Newtown, USA), particle size test equipment and zeta potential particle size analyzer (Malvern Panalytical, USA).), magnetic stirrer (Thermo Scientific, China), pH meter (Eutech Instruments, Ecoscan hand-held series, Singapore), centrifuge (SPLC Series, Gemmy 8 Hole, Taiwan), analytical balance (Ohaus), glass tools (Pyrex, Japan) and non-glass contained in the laboratory.

\section{Preparation of Myricetin Nano-phytosomes}

Nano-phytosomes were prepared by dissolving myricetin in $10 \mathrm{ml}$ p. a ethanol, phosphatidylcholine dissolved in $10 \mathrm{ml} \mathrm{p}$. a ethanol and cholesterol dissolving in dichloromethane $\mathrm{p}$. a. Phytoactive solutions and phospholipids were mixed using a magnetic stirrer at $35^{\circ} \mathrm{C}$ at $2000 \mathrm{rpm}$ for 10 minute, the nano-phytosome complex was made a thin layer on a rotary evaporator at $55^{\circ} \mathrm{C}$ at $50 \mathrm{rpm}$ until the acetone and dichloromethan phases evaporated. The colloid dispersion formed was sonicated using probe sonication. After obtaining myricetin nanophytosomes, a freeze-dry was carried out to obtain myricetin nanophytosome powder. Freeze-dry was carried out using a temperature of $-80^{\circ} \mathrm{C}$ for $48 \mathrm{~h}$ with a high-pressure vacum pump.

\section{Table 1: Myricetin nano-phytosome formula}

\begin{tabular}{ll}
\hline Materials & Weight $^{*}$ \\
\hline Myricetin & $10 \mathrm{mg}$ \\
Phospholipid & $48 \mathrm{mg}$ \\
Cholesterol & $5 \mathrm{mg}$ \\
Aqua Pro Injection & $20 \mathrm{ml}$ \\
\hline
\end{tabular}

*Ratio of myricetin: phosphatidylcholine: cholesterol (1: 2: 0.4)

\section{Characterization of myricetin nano-phytosomes}

\section{Particle measurement}

The size of the nanoparticles was measured using the PSA tool. To find out the zeta potential value, it was measured using a zeta potential analyzer.

\section{Absorption efficiency}

The absorption efficiency was determined by centrifuging the nanophytosome and the supernatant separated. The pellets obtained were washed and then resuspended to obtain phytosomes that were free from absorbed drugs. Phytosomes were centrifuged for $50 \mathrm{~min}$ at $5000 \mathrm{rpm}$ to separate the unabsorbed drug. The amount of free drug (FD0) is determined in the supernatant. The supernatant resulted from centrifugation was leveled using a UV-Vis spectrophotometer [15].

\section{Preparation of peel-off gel mask}

PVA was developed with aqua dest at $90^{\circ} \mathrm{C}$ until it fully expanded, then homogenized (M1). Next, expand the carbopol with water, add propylenglycol and stirring TEA to form a gel base (M2). Myricetin nano-phytosome powder was dissolved with aqua pro injection until dissolved (M3). M1 was added to M2 while still stirring, then M3 was added, and finally $100 \mathrm{ml}$ of aquadest ad was added to form a homogeneous gel mass.

\section{Physical quality test of the peel-off gel mask}

The physical quality test of the gel peel-off mask formula was carried out at a temperature of $25-30^{\circ} \mathrm{C}$ [16]. This test includes organoleptic test, homogeneity, $\mathrm{pH}$, viscosity, adhesion test, and drying time.

Table 2: Peel-off gel mask formula

\begin{tabular}{lllll}
\hline Materials & Formula 1 (\%) & Formula 2 (\%) & Formula 3 (\%) & Formula 4 (\%) \\
\hline Myricetin Nanophytosome Powder & 0.0625 & 0.0625 & 0.0625 & - \\
PVA & 3.5 & 7 & 14 & 3.5 \\
Carbopol 940 & 1 & 1 & 1 & 1 \\
Propilenglikol & 6 & 6 & 6 & 6 \\
Opthipen & 1 & 1 & 1 & 1 \\
TEA & 2 & 2 & 2 & 2 \\
Aquadest ad & 100 & 100 & 100 & 100 \\
\hline
\end{tabular}

\section{Antioxidant activity test}

The method for determining antioxidant activity was the DPPH 1,1diphenyl2-picrylhydrazyl $(\alpha, \alpha$-diphenyl- $\beta$-picrylhydrazyl) method [17]. The antioxidant activity test using this method can be observed based on the loss of purple color due to the reduction of DPPH by active substances containing antioxidant activity. The color intensity of the test solution was measured by UV-Vis spectrophotometry at a wavelength of $516 \mathrm{~nm}$. The percent (\%) inhibition yield is substituted in the linear equation.

\section{RESULTS AND DISCUSSION}

\section{Myricetin nano-phytosome characterization}

Particle size and size distribution characteristics are critical in nanoparticle systems. Particle size and size distribution determined in vivo distribution, toxicity, and targeting ability in nanoparticle systems. In addition, particle size and size distribution can also affect drug delivery, drug release, and nanoparticle stability [18]. The results showed that the concentration ratio of myricetin: phosphatidylcholine: cholesterol (1: 2: 0.4 ) had a particle size of
$374.6 \mathrm{~nm}$, where the particle size was in the range of the nanoparticle size, which was below $1000 \mathrm{~nm}$ [13].

Values that show the breadth of particle size distribution in preparation are called the Polydispers or IP Index. IP $>0.5$ represents a nanoparticle system with a very broad particle size distribution (polydispersion), whereas IP has a value of $<0.5$ for monodispersed particles. The best polydispersity index value is $<0.5$ because the smaller the IP value, the better the stability of the nano-phytosome. The polydispersity index value was 0.397 , so that the myricetin nanophytosome produced had a homogeneous and stable particle size.

The zeta potential measurement results are-16.67, negative results indicate that the phosphatidylcholine used is negatively charged. The absorption efficiency aims to determine the amount of myricetin absorbed in the nano-phytosome carrier system. The drug delivery system must have a high drug loading capacity and last a long time. Drug loading capacity (adsorption efficiency) is generally expressed in terms of the percent of drug absorbed in the fat phase to the added drug [19]. The results of the analysis can be seen in table 3 . These results have a good absorption frequency range, namely $>80 \%$.

Table 3: Results of myricetin nano-phytosome characterization

\begin{tabular}{llll}
\hline Particle size (nm) $^{*}$ & Polydisperse index $^{*}$ & Zeta potential (mV) $^{*}$ & Absorption efficiency (\%) $^{*}$ \\
\hline $374.6 \pm 3.46$ & $0.397 \pm 0.02$ & $-16.67 \pm 2.52$ & $99.27 \pm 0.25$ \\
\hline
\end{tabular}

*The data are written the average value and the SD value of each formula. 
Evaluation of the physical quality of the myricetin nanophytosome gel peel-off mask

\section{Organoleptic test}

The physical appearance of peel-off gel masks on F1, F2 and F3 containing myricetin nano-phytosomes have red color, while F4 which did not contain myricetin $\mathrm{K}(-)$ nano-phytosome powder looked clear (colorless). The resulting four peel-off gel masks are odorless, and the resulting four formulas are in gel form.

Homogeneity examination aims to observe the presence or absence of coarse particles on the preparation. Of the four preparations, F1, F2, F3 and F4 have good homogeneity, because there are no coarse particles in the peel-off gel mask preparation.

Table 4: Organoleptic test results

\begin{tabular}{llll}
\hline Test & Formula 1 & Formula 2 & Formula 3 \\
\hline Color & Red & Red & Red \\
Smell & No smell & No smell & No smell \\
Consistency & Gel & Gel & Gel \\
\hline
\end{tabular}
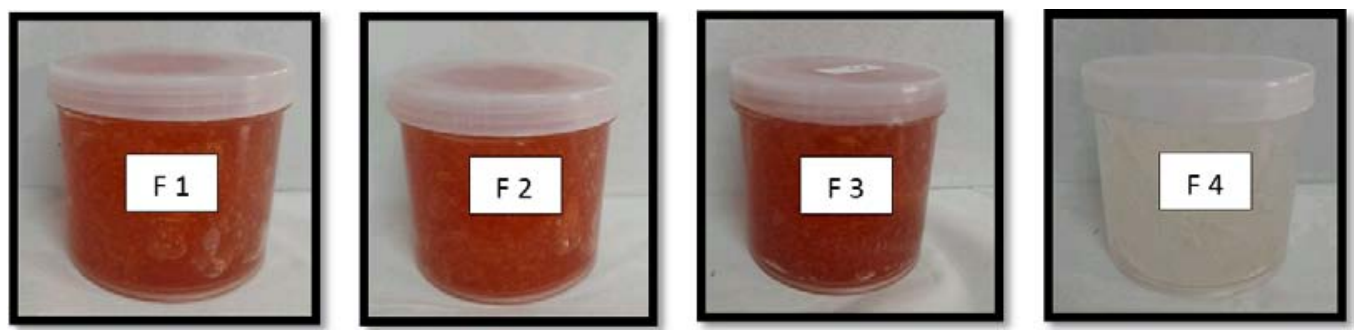

Fig. 1: Peel-off gel mask preparation

Table 5: The results of the physical quality test of the peel-off gel mask

\begin{tabular}{lllll}
\hline Formula & Homogeneity & pH & Viscosity (d. Pas) & Adhesion (seconds) $^{*}$ Drying time (min) $^{*}$ \\
\hline Formula 1 & Homogenous & 6 & 500 & $5.17 \pm 0.7$ \\
Formula 2 & Homogenous & 6 & 700 & $13.64 \pm 1.5$ \\
Formula 3 & Homogenous & 6 & 900 & $99.27 \pm 28.6$ \\
Formula 4 & Homogenous & 6 & 500 & $18.31 \pm 0.9$ \\
\hline
\end{tabular}

${ }^{*}$ The data are written the average value and the SD value of each formula.

The $\mathrm{pH}$ test aims to determine the safety of the gel preparation when used so that it does not irritate the skin [20]. Topical preparations must meet these requirements, because if the $\mathrm{pH}$ is too alkaline it will cause the skin to become scaly, on the other hand, if the skin $\mathrm{pH}$ is too acidic it can cause skin irritation [21]. Based on table 5, it is known that the $\mathrm{pH}$ test results for each gel preparation are 6. These results are as expected, where the two cream preparations have a $\mathrm{pH}$ that matches the normal $\mathrm{pH}$ range of the skin, namely 4.5-6.5.

The viscosity test is carried out to determine the viscosity level of the resulting preparation. Viscosity is the expression of a liquid to flow, the higher the viscosity the harder it is to flow/the greater the resistance [22]. Based on the data in the table above, it is known that the preparations have values of F1 500 d. Pa. s, F2 700 d. Pa. s, and F3 900 d. Pas and F4 500 d. Pas. Formula 3 has a higher viscosity than other formulas, so the gel with a higher viscosity will be more difficult to apply to the skin. F3 has a higher viscosity value because it contains a high concentration of PVA gelling agent so that the consistency is much higher compared to other formulas.

The purpose of adhesion is to determine the time it takes for the preparation to adhere to the skin, the longer it takes, the longer the working power of the drug. From the observations, it can be seen that the adhesive power of the peel-off gel with a greater PVA concentration has a higher adhesion value than the low concentration PVA base. The stickiness of the peel-off gel is influenced by the viscosity, the higher the viscosity, the longer the sticking time of the cream on the skin.

The gel dry time test aims to determine how long it takes the gel to dry on the skin surface and forms a film layer. The dry time of the four peel-off mask gel formulas ranged from $16.6 \mathrm{~min}$ to $22.08 \mathrm{~min}$. Formula 3 containing high PVA concentrations has a faster dry time than the other three formulas that contain low PVA, namely F1, F2 and F3. This is because the greater the concentration of PVA, the higher the alcohol content, so that it evaporates faster than the low PVA concentration, from the data obtained that the four gel peel-off mask formulas meet the good dry time of the gel peel-off mask, which is between 15-30 minute.

\section{Antioxidant activity test}

The method of determining antioxidant activity was the DPPH method 1,1-diphenyl2-picrylhydrazyl $\quad(\alpha, \quad \alpha$-diphenyl- $\beta$ pikrilhidrazil). DPPH is a free radical that is stable and does not form dimers due to delocalization of free electrons throughout the molecule. The antioxidant activity test using this method can be observed based on the loss of purple color due to the reduction of DPPH by active substances containing antioxidant activity. The color intensity of the test solution was measured by UV-Vis spectrophotometry at a wavelength of $516 \mathrm{~nm}$. The percent (\%) inhibition yield is substituted in the linear equation. $\mathrm{IC}_{50}$ is defined as the amount of antioxidants required to reduce the initial DPPH concentration by $50 \%$.

Compounds are said to be very strong antioxidants if the $\mathrm{IC}_{50}$ value is less than $50 \mathrm{ppm}\left(\mathrm{IC}_{50}<50 \mathrm{ppm}\right)$, strong ( $\left.50 \mathrm{ppm}<\mathrm{IC}_{50}<100 \mathrm{ppm}\right)$, moderate $\left(100 \mathrm{ppm}<\mathrm{IC} \mathrm{I}_{50}<150 \mathrm{ppm}\right)$, weak $\left(150 \mathrm{ppm}<\mathrm{IC}_{50}<200\right.$ ppm), and very weak (IC $50>200$ ppm) (Molyneux 2004).

One of the mechanisms of action of antioxidant compounds in reducing radical compounds is by donating electrons to these unstable compounds so that, they can change unstable free radicals into more stable compounds. Myricetin nano-phytosome peel-off gel mask has very strong antioxidant activity with $\mathrm{IC}_{50}$ values of F1 14.8 ppm, F2 $15.37 \mathrm{ppm}$, and F3 $15.87 \mathrm{ppm}$. This shows that the myricetin compounds contained in the gel peel-off mask still provides very strong antioxidant activity. 


\section{CONCLUSION}

Based on the results obtained, it can be concluded that the myricetin nano-phytosome can be formulated into a gel peel-off mask, Formula 2 with a $7 \%$ PVA concentration produces the best physical quality of the peel-off gel mask, the three gel peel-off mask formulas have very strong antioxidant activity with an $\mathrm{IC}_{50}$ value of F1 $14.8 \mathrm{ppm}, \mathrm{F} 2$ $15.37 \mathrm{ppm}$, and F3 $15.87 \mathrm{ppm}$.

\section{RECOMENDATION}

Further research needs to be carried out to test the stability of the myricetin nano-phytosome peeling gel to see the physical stability of the preparation and drug release test.

\section{ACKNOWLEDGMENT}

This research was supported and funded by the Ministry of Research and Technology of the Republic of Indonesia and this research was also supported by PKPT team.

\section{FUNDING}

Nil

\section{AUTHORS CONTRIBUTIONS}

All the authors have contributed equally.

\section{CONFLICT OF INTERESTS}

Declared none

\section{REFERENCES}

1. Pratiwi L, Wahdaningsih S. Formulation and antioxidant activity facial mask gel peel-off papaya fruit methanol extract (Carica papaya L.). Pharm Med J 2008;1. DOI:10.35799/ pmj.1.2.2018.21643.

2. Armadany FI, Hasnawati, Sirait M. Antioxidant peel-off gel mask formulation from tomato extract (Solanum lycopersicum L. var. cucurbita). Pharm Pharm Sci Health Magazine 2020;2:29-32.

3. Rahmawanty D, Yulianti N, Fitriana M. Formulation and evaluation of peel-off face masks containing quercetin with various gelatin concentrations. J Med Farm 2015;12:17-32.

4. Hasyim N, Faradiba, Gina AB. Formulation of wuluh starfruit juice gel (Averrhoa bilimbi L.). Pharm Pharmacol Magazine 2011;15:5-9.

5. Chakraborty S, Vadakkekara A, George N, Bhagyasree T, Mary L. Application and stability evaluation of polymer blends in cosmetics. Int J Res Appl Sci Eng Tech 2017;5:849-61.

6. Andre B. Green clay and oleo vera peel of facial masks: response surface methodology applied to the formulation design. Am Assoc of Pharm Sci 2013;14:445-455.
7. Anese M, Lara M, Maria CN. Antioxidant properties of tomato juice as accented by heating. J Sci Food Agric 1999;79:750-4.

8. Gaber DM, Nafee N, Abdallah OY. Myricetin solid lipid nanoparticles: Stability assurance from system preparation to site of action. Eur J Pharm Sci 2017;109:569-80.

9. Hong C, Dang Y, Lin G, Yao Y, Li G, Ji G, et al. Effects of stabilizing agents on the development of myricetin nanosuspension and its characterization: an in vitro and in vivo evaluation. Int J Pharm 2014;477:251-60.

10. Ramadon D, Mun'im A. Utilization of nanotechnology in drug delivery system for natural products. JIFI 2016;14:118-27.

11. Rasaie S. Nano phytosomes of quercetin: a promising formulation for the fortification of food products with antioxidants. Pharm Sci 2014;20:96-101.

12. Jain N, Gupta BP, Thakur N, Jain R, Banweer J, Jain D, et al. Phytosome: a novel drug delivery system for herbal medicine. Int J Pharm Sci Drug Res 2010;2:224-8.

13. Garg R, Kaur S, Ritika, Khatoon S, Naina, Verma H. A complete and updated review on various types of drug delivery systems. Int J Apllied Pharm 2020;12:1-16.

14. Ghanbarzadeh B. Nano-phytosome as a potential food-grade delivery system. Food Biosci 2016;15:126-35.

15. Pham, Thi T. Colloid and surfaces B: Biointerfaces, liposome and niosome preparation using a membran contractor for scale-up. France 2012;94:15-21.

16. Indrawati $\mathrm{T}$, Hajard I, Pratami DK. Skincare cream preparation and evaluation of pare (Momordica Charantia) leaves using three difference base. Int J Appl Pharm 2020;12:162-6.

17. Harmita H, Iskandarsyah, Murti FZ. Effect of transfersome on the stability and antioxidant activity of glutathione in antiaging creams. Int J Appl Pharm 2020;12:149-55.

18. Mohanraj VJ, Chen Y. Nanoparticles-a review. J Pharm Res 2006;5:561-73.

19. Gregoriadis, Gregory. Liposome technology: liposome preparation and related techniques. Informa Healthcare USA 2007;3:21-32.

20. Juwita AP, Yamlean P, Edy HJ. Seagrass leaf ethanol extract cream formulation (Syringodium isoetifolium). Thesis Sam Ratulangi University; 2013.

21. Swastika A, Mufrod, Puwanto. Antioxidant activity of tomato extract cream (Solanum lycopersicum L.). Trad Med J 2013;18:132-40.

22. Barokah R. HLB emulgator price variation based on comparison of tween 80 and span 80 against physical and chemical properties of Curcuma mangga Val ethanol extract cream as sunscreen. Surakarta: Faculty of Mathematics and Natural Sciences, Sebelas Maret University; 2014. 